\title{
EMOCIONES Y COGNICIONES DE UN HOMBRE CON HIPERFAGIA: ESTUDIO DE CASO
}

\author{
Aura Silva Aragón, Silvia Concepción Rendón López, Martha Elena Diego Velasco \\ y Guadalupe Martínez Cruz \\ Facultad de Estudios Superiores Iztacala, UNAM \\ México
}

\begin{abstract}
RESUMEN
El presente trabajo se realizó siguiendo la metodología cualitativa, y tuvo como objetivo indagar las emociones y cogniciones que confluyen en un hombre que ingiere alimento de manera excesiva, así como entender la relación que existe entre el individuo y la comida. Lo anterior se logró mediante una minuciosa entrevista a un hombre de 40 años que presenta hiperfagia. A raíz del análisis de la entrevista desde el enfoque fenomenológico, se puede decir que las emociones más presentes se relacionan con la ansiedad, el enojo y el remordimiento; las cogniciones giran en torno a la evasión, responsabilizar a otros de su ingesta, y, además, actúan como un justificante en sus hábitos alimenticios; la percepción que tiene de sí mismo es negativa en cuanto a aspectos físicos, emotivos y sociales, y positiva en cuanto a capacidad mental y laboral. Mediante esta investigación se logró obtener información de primera mano respecto a lo que piensa y siente una persona que come en exceso; asimismo fue posible conocer el trasfondo de una conducta que ha quedado rezagada y de la cual hay pocos estudios.
\end{abstract}

\section{Palabras Clave:}

ingesta excesiva, ingesta emocional, obesidad, cogniciones, emociones, ansiedad

\section{EMOTIONS AND COGNITIONS OF A MAN WITH HYPERPHAGIA: A CASE STUDY}

\begin{abstract}
The present work was done following the qualitative methodology and had as objective to know the emotions and cognitions that come together in a person who ingests food excessively, as well as to understand the relationship that exists between the individual and the food. This was achieved by conducting an in-depth interview with a 40-year-old man with hyperphagia. Following the analysis of the interview from the phenomenological approach, it can be mentioned that the most present emotions are related to anxiety, anger and remorse; Cognitions revolve around evasion, make others responsible for their intake, and also act as a justifier in their eating habits; his perception of himself is negative in terms of physical, emotional and social aspects, and positive in terms of mental and work ability. Through this research, first-hand information was obtained about what a person who eats in excess thinks and feels, and it was possible to know the background of a behavior that has lagged behind, on which there are few studies.
\end{abstract}

Keywords:

excessive intake, emotional intake, obesity, cognitions, emotions, anxiety

Bitácora del Artículo:

| Recibido: 28 de Febrero de 2018 | Aceptado: Noviembre de 2018 | Publicado en línea: Julio-Diciembre de 2018 | 


\title{
Autoría y Derechos de Propiedad Intelectual
}

\section{EMOCIONES Y COGNICIONES DE UN HOMBRE CON HIPERFAGIA: ESTUDIO DE CASO}

\author{
Aura Silva Aragón, Silvia Concepción Rendón López, Martha Elena Diego Velasco \\ y Guadalupe Martínez Cruz \\ Facultad de Estudios Superiores Iztacala, UNAM \\ México
}

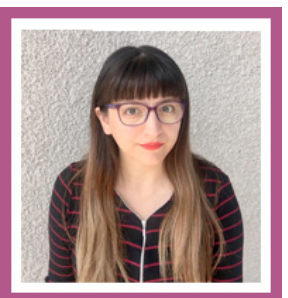

Aura Silva Aragón SUAyED FES Iztacala, UNAM

Correo: psic.aura.silva@gmail.com

Licenciada en Psicología por la FES Iztacala. Maestra en psicología con Residencia en Terapia Familiar por la UNAM. Tutora en del Sistema de Universidad Abierta y a Distancia de la UNAM. Actualmente colabora con el Observatorio de Violencia de Género y Social del Estado de Aguascalientes.

Ver más...

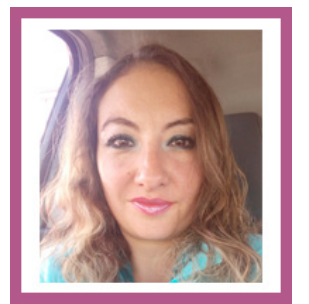

Silvia Concepción Rendón López SUAyED FES Iztacala, UNAM

Correo: silviac.rendon@gmail.com

Perito en Criminalística por la Asociación Latinoamericana de Medicina Legal Deontología Médica e Iberoamericana de Ciencias. Licenciada en Derecho por la Universidad Autónoma de Hidalgo. Actualmente es estudiante de psicología del SUAyED de la FES Iztacala, UNAM.

Ver más...

\section{CONTRIBUCIÓN DE LAS AUTORAS}

Aura Silva dirigió, asesoró y revisó la elaboración de la investigación y del artículo. | Silvia Rendón estuvo a cargo de la realización de la entrevista y redacción del artículo. | Martha Diego realizó trabajo de campo y participó en la redacción del artículo. | Guadalupe Martínez realizó trabajo de campo y participó en la redacción del artículo.

\section{AgRADECIMIENTOS}

Las autoras agradecen la participación sincera y desinteresada de Alejandro ya que gracias a su apoyo y disposición fue posible realizar la presente investigación.

\section{Datos de Filiación de LAS Autoras}

Sistema Universidad Abierta y Educación a Distancia de la Facultad de Estudios Superiores Iztcala, UNAM.

Copyright: (C) 2018 Silva-Aragón, A. Rendón-López, S.C., Diego-Velasco, M.E., \& Martínez-Cruz, G.

Este es un artículo de acceso abierto distribuido bajo los términos de la licencia Creative Commons Reconocimiento-NoComercial 4.0 Internacional, por lo que su contenido gráfico y escrito se puede compartir, copiar y redistribuir total o parcialmente sin necesidad de permiso expreso de sus autoras con la única condición de que no se puede usar con fines directamente comerciales y los términos legales de cualquier trabajo derivado deben ser los mismos que se expresan en la presente declaración. La única condición es que se cite la fuente con referencia a la Revista Digital Internacional de Psicología y Ciencia Social y a sus autoras. 


\section{TABLA DE CONTENIDO}

Participante, 27

Materiales, 27

Método de recolección de información, 27

Procedimiento, 28 


\section{INTRODUCCIÓN}

$\mathrm{E}$ I alimento para el ser humano es una necesidad, un gusto, un festejo, un oficio; un símbolo de tradición, de cultura o de herencia familiar; el lazo que promueve la unión social y la convivencia; denota estatus social y económico; está presente en nuestras vidas todos los días y es tema de orgullo y anécdotas. Es un arte, un don de comparación de sabores, e incluso forma parte esencial de planificaciones.

La relación de las personas con el alimento comienza desde el vientre materno; $y$ al nacer, alimentarse es el primer instinto de un bebé que no sólo satisface el hambre sino las necesidades psicológicas básicas de seguridad, protección y contacto humano. El alimento queda así grabado en una relación sujeto-alimento-afecto que nos seguirá por el resto de nuestra vida (Santamaría et al., 2009). La forma de alimentarse se genera desde la esfera familiar, en donde se fomentan los hábitos de comer por tener hambre y saciarse o comer en exceso de una manera descontrolada.

Sin embargo, comer es una conducta compleja generada no sólo por el hambre sino también por varios factores biológicos, psicológicos, emocionales, nutricionales, sociales y económicos (Sirota, 2012). Mientras que la obesidad y los padecimientos asociados con el sobrepeso representan importantes factores de mortalidad en algunos países, en otros el mal coexiste con trastornos de alimentación como bulimia o anorexia.

Respecto al problema del comer en exceso, tiene tan variados factores que existen diversas investigaciones con datos concluyentes, y todas ellas con una diferente causal como objeto de estudio. Por ejemplo, en varias investigaciones (Álvarez, Franco, López, Mancilla y Vázquez, 2009; Mancilla et al., 2010; Salaberria, Rodríguez y Cruz, 2007) se muestra que la insatisfacción corporal es motivada por influencias publicitarias y socioculturales, así como una negativa autopercepción de la imagen; esta es el detonante para los trastornos alimentarios donde se busca una figura estética aceptable socialmente. En otro estudio (Pascual, Etxebarria, Cruz y Echeburúa, 2011) se afirma que la ansiedad, la alexitimia y la autoestima son las únicas variables de las que hay constancia que desarrollan los trastornos alimentarios de anorexia y bulimia. Por su parte la hiperfagia (comer en exceso) tiene como causa la relación con los factores socioculturales, publicitarios de medios de comunicación, emocionales, referen- tes a hábitos tanto alimenticios como deportivos, factores genéticos y hormonales, etcétera, que han generado un sin número de ensayos.

Aparicio (2009), basado en la filosofía de Schopenhauer, hace un análisis de los efectos del consumismo. Este autor indica que los medios de comunicación promueven la ingesta en jóvenes de bebidas y botanas altas en calorías y azúcares, y un menor consumo de frutas de agua y leche. Desde niños se permite un mayor consumo de alimentos atractivos por su sabor, comportamiento fomentado por la televisión que hace una segmentación del mercado de alimentos y bebidas. A los niños se les incita a consumir alimentos con alto contenido de azúcar, los cuales con frecuencia tienen sabor agradable y mayor aceptación. A las personas de mayor edad se les presentan productos alimenticios relacionados con el peso corporal (Pérez, Rivera y Ortiz, 2010). Los medios de comunicación no sólo han sido estudiados como factor que promueve la mala alimentación, sino que promueve el sedentarismo.

Según la doctora Marion Nestlé, profesora en nutrición de la Universidad de Nueva York y autora de libros como Food Politics y Safe Food (University of California Press, 2002; citado en López, 2004), la industria alimentaria actual es la principal responsable de que hoy se coma en exceso, porque en este mundo, regido por las leyes de la oferta y la demanda, la única manera en que puede subsistir y competir esta industria es promoviendo la demanda de sus productos; para ello, las distintas empresas se apoyan en estrategias, no siempre apegadas a la ética.

El trabajo de Utter, Scragg y Schaaf (2006; citado por Aparicio, 2009) indica que las probabilidades que tienen las niñas, niños y adolescentes de desarrollar sobrepeso $u$ obesidad se incrementan conforme aumenta la duración del tiempo que ven la televisión. Al igual que Gracia (2009), estos autores acusan a la industrialización y a las tecnologías de ser los factores que promueven el ocio, sedentarismo y publicitan la ingesta de alimentos altos en calorías y grasas.

Es necesario aclarar que no todas las personas que comen de manera excesiva presentan sobrepeso, ni todas las personas con sobrepeso presentan problemas en su manera de comer; sin embargo, la probabilidad de ganar sobrepeso debido a la hiperfagia es alta y considerable. De acuerdo con la United Nations Children's Fund [UNICEF] (s.f.), sólo por mencionar algunos datos relacionados con el tema, México ocupa el primer lugar mundial en obesidad infantil y el segundo en obesidad en personas adultas. El sobrepeso es un problema que afecta a uno de cada tres adolescentes de entre 12 y 19 años. La obesidad y sobrepeso son un factor de riesgo de enfermedades car- 
diovasculares (principal causa de muerte en el año 2012), trastornos del aparato locomotor, algunos tipos de cáncer y muerte prematura en personas adultas.

Desde la perspectiva biológica se entiende que la conducta alimentaria está directamente relacionada con variables del tipo biológico y/o fisiológico. Por ejemplo, en el hipotálamo los núcleos ventromedial y lateral son denominados — dada sus funciones regulatorias que controlan la ingesta de alimento- centros de hambre y centros de saciedad (Santacoloma y Quiroga, 2009). Ponce (2007) señala como factor que favorece la obesidad la insensibilidad a la hormona leptina, que actúa en el cerebro produciendo una disminución en la ingesta a través de otro mediador: el neuropéptido; de acuerdo con este autor, las personas con obesidad tienen altos niveles de esta hormona, pero no actúa eficazmente, por lo que la sensación de saciedad no llega al cerebro; además, la poca capacidad de aprovechar mejor la energía de los alimentos ocasiona la acumulación de grasa y está determinada por la herencia genética de cada persona.

Otra explicación para el hábito de comer en exceso con bases biológicas es el estímulo que se genera en las neuronas cuando azúcar, grasa o sal son puestas en la boca. Las neuronas están conectadas en circuitos y se comunican entre ellas para crear sensaciones, emociones, guardar información y controlar el comportamiento, las cuales al ser estimuladas por la comida responden ante el sabor mediante señales eléctricas y químicas que segregan en el cerebro; de esta manera las neuronas codifican el alimento como un reforzante; por ejemplo, la sacarina responde de manera vigorosa. Entre más dulce es la sacarosa, más neuronas van a reaccionar y el deseo de consumirlo se torna más intenso. Un solo alimento puede estimular diferentes neuronas simultáneamente. El efecto acumulativo de este estímulo sensorial ocasiona que las neuronas deseen más, motivando a la persona a comer más para alcanzar la misma sensación (Kessler, 2009).

Algunos estudios sugieren que en la regulación del apetito y la alimentación participan sustancias como el ácido gamma-aminobutírico, que al unirse al principal neurotransmisor inhibitorio cerebral nombrado opioides, influyen en la conducta alimentaria. Aunado a esto, al comer alimentos altos en grasa o azúcar, los opioides pueden ayudar a aliviar el estrés o el dolor. Es decir, estos alimentos pueden ayudar a sentirnos mejor, incrementando el gusto por ellos (Kessler, 2009).

Estos cambios son componentes clave en el balance inducido por el consumo compulsivo (Miranda, 2012). El estímulo generado por las neuronas al comer azúcar, sal y grasa, sirve como reforzante de la conducta alimentaria. La comida gratificante tiende a ser reforzante manteniéndonos en un estado de deseo constante (Kessler, 2009). Cuando un alimento nos gusta, el agrado viene a nivel olfativo, visual, gustativo y de textura. Así, una pequeña pista de lo que viene a continuación puede estimular la urgencia de querer más. La asociación entre estas pistas y la comida se hace cada vez más fuerte, causando una fijación mental intensa en la obtención del alimento que se nos antoja; entre más es el deseo, mayor el placer al satisfacerlo, generando un ciclo continuo de señal-deseo-recompensa que eventualmente se convierte en un mal hábito alimenticio.

Estas evidencias indican que el reforzamiento por comida, no el hambre, es la principal fuerza que motiva a comer más allá de la saciedad. Los "factores estrechamente relacionados con la motivación, el reconocimiento de premios y castigos, así como la disponibilidad y la carencia, física o emocional, de determinados componentes de la dieta, ejercen una influencia significativa en la conducta alimenticia" (Miranda, 2012, p. 5). La selección de alimentos, que resultó ser una herramienta de aprendizaje evolutiva, actualmente genera el deseo de consumir más alimentos apetitosos independientemente de su contenido nutritivo. Por último, cuando una persona atraviesa periodos de abstinencia de algunos alimentos, puede experimentar malestar, cuyo alivio motiva el consumo recurrente compulsivo de alimentos (Fortuna, 2010, citado en Miranda, 2012).

El componente afectivo de la relación entre emociones y alimentación no es simple; los estados emocionales y de ánimo pueden influir en la conducta alimentaria, y a su vez la alimentación puede modificar las emociones y estados de ánimo (Gibson, 2006, citado en Peña y Reidl, 2015). Quizá por eso las emociones como detonantes de la ingesta excesiva de alimento es la explicación más recurrida y estudiada para la hiperfagia. A veces se puede comer no por hambre, sino para liberar la sobrecarga de emociones como la frustración, estrés, enojo e incluso la felicidad mediante la alimentación en exceso, "de modo que es fundamental conocer los aspectos psicológicos en la conducta de comer, en el desarrollo de hábitos, aprendiendo a manejar las emociones, entendiendo su relación con los pensamientos, los sentimientos y las conductas" (Dongil y Cano, 2014, p. 13). Algunas características de comer de manera emocional son: el hambre repentina, que ataca de pronto y con rapidez, antojos de comida específica generalmente no saludable; urgencia incontenible por comer sin que medie tanto tiempo de la última comida; asociación del hambre con emociones negativas recientes; inconsciencia en lo que se come; comer aún después de la saciación; hambre generada en la mente y 
no en el estómago, y, finalmente, sentirse culpable después de comer (The Blokehead, 2015).

Debido a la diversidad de problemas y circunstancias estresantes a las que a diario el ser humano está expuesto, suele presentar emociones negativas, y de una u otra forma en ocasiones busca salida sin considerar que las consecuencias pueden ser mayores. "Muchas personas aprenden a reducir su malestar emocional comiendo compulsivamente o consumiendo alimentos con alto nivel calórico con el fin de bloquear emociones desagradables intensas, como ansiedad, frustración, apatía, tristeza, ira, impotencia, etc." (Dongil y Cano, 2014, p. 28).

Como se ha revisado, tanto Miranda (2012) como Kessler (2009) teorizan que los alimentos altos en grasas, sales y azúcares actúan como reforzantes conductuales al segregar dopamina, que genera emociones agradables que, a su vez, motivan la hiperfagia. Sin embargo, un enfoque distinto lo expone Ortuno (2015) al presentar a las emociones como el estímulo y no el refuerzo de la ingesta excesiva de alimentos, es decir, la comida es la que tiene una causante emocional, y que, como consecuencia, buscamos un alimento determinado para remontarnos a una memoria determinada:

La comida ya no tiene solamente un significado fisiológico, sino emocional, y cobra un papel protagonista cuando nos sentimos bien. Asociamos, de esta forma, la comida con emociones positivas, y esta asociación permanece en el tiempo. Así, la mayoría de las veces, cuando tenemos ansiedad por comer más o tomar dulces, en realidad lo que tenemos es hambre de compañía, de afecto, de tranquilidad, de seguridad (Ortuno, 2015, p. 21).

Para Ortuno (2015) existen tres procesos durante el hábito de la comida: hambre fisiológica, la asociación y la apetencia. La apetencia es la necesidad emocional de consumir determinado alimento, y cuando tenemos problemas emocionales la apetencia se detona y comenzamos a comer sin freno del repertorio de alimentos placenteros que en la mente tenemos asociados con la intención de retrotraernos a las emociones agradables que éstos generan:

El antojo de una galleta, por ejemplo, no sólo viene de la necesidad de comer algo dulce sino de su significado. Éste puede reflejar no sólo el deseo de la persona por la golosina, sino también el deseo de amor, confort, sensación de pertenencia, anestesia emocional, e incluso estatus social (Sirota, 2012, p. 2).
En un estudio encabezado por Peña y Reidl (2015) se identificaron los alimentos consumidos con mayor frecuencia por jóvenes de 22 años y las emociones que experimentan durante su ingesta. Se identificó que quienes comen emocionalmente incrementan el consumo de los alimentos en respuesta a sus emociones tanto negativas como positivas, en contraste con lo que se solía creer, que sólo las emociones negativas inducen la hiperfagia. El dato sobresaliente de esta investigación es la identificación de emociones generadas durante el consumo, mismas que se han dejado a un lado en diversos estudios anteriores; entre las emociones que se experimentaron con mayor frecuencia durante la alimentación, están alegría, alivio, amor, arrepentimiento, asco, culpa, disfrute, felicidad, placer, remordimiento, repulsión y ternura. Debido a que las personas pueden no notar los cambios en su conducta alimentaria como consecuencia de su estado de ánimo, las autoras sugieren enseñar a los pacientes a identificar y regular sus emociones para hacer efectiva una intervención nutricional.

Por otra parte, la rutina diaria a que se somete cada persona por cuestiones laborales y escolares puede crear un hábito alimentario condicionado a lugares, olores u horarios. Esta rutina individual para cada persona puede afectar el comportamiento o el hábito alimenticio (Santalacoma y Quiroga, 2009). Por ejemplo, una persona que se malpasa por cuestiones laborales puede terminar dándose un gran atracón más allá de la saciedad como consecuencia de las largas horas que su cuerpo ha pasado sin ingerir alimentos. A estos lapsos sin alimento se denomina "privación alimentaria" (Vázquez, López, Martínez, Rodríguez, Aguilera y Espinoza, 2015).

Si una persona es sometida a un estado de privación, emitirá una respuesta reguladora para equilibrar su medio interno y externo, es decir, cuando una persona ha sido privada de algunos alimentos, tiene una necesidad particular por esos alimentos que antes le fueron negados, convirtiéndola en un reforzante significativo. Esta característica personal individual puede generarse después de una dieta restrictiva. Una historia de restricciones y sobreconsumo de alimentos puede contribuir en algunas personas a una conducta de hiperfagia. La actividad cíclica de privación, seguida de episodios de libre acceso a la comida, ocasiona desequilibrio alimentario (Vázquez et al., 2015).

Howard y Porzelius (1999, citado por Vázquez et al., 2015) indican que el atracón está relacionado con la frecuencia de las dietas a las que la persona se sometió; las personas que comenzaron a hacer dieta a edades más tempranas y pasaron más tiempo esforzándose por per- 
der peso son las que tienen más riesgo de presentar una conducta severa de atracón, y por tanto de sobrepeso.

Otro factor personal de la conducta alimentaria está en función de variables ambientales; por ejemplo, a diferencia de países asiáticos donde basan su comida en cereales bajos en grasa, en México, el multiculturalismo de la gastronomía presenta un alto contenido de grasas, sabores saturados y harina, variedad y colorido que hacen atractiva la comida, además de ser alimentos que encontramos en cualquier esquina y a bajo costo. Así mismo, las personas que viven en las ciudades tienen el doble de probabilidades de padecer trastornos que quienes que viven en zonas rurales.

Como hemos expuesto hasta ahora, la conducta de comer en exceso ha sido analizada desde múltiples enfoques y criterios. Desde el aburrimiento y el ocio hasta la celebración dichosa entre bocadillos, podemos puntualizar que, en muchos textos, de manera indirecta o directa mencionan a las emociones como elemento importante del fenómeno de comer en exceso.

Con base en lo anterior, las preguntas que guiaron esta investigación fueron: ¿cuáles son las emociones y cogniciones asociadas a la ingesta excesiva de alimentos?, ¿cuáles son las emociones que se presentan cuando le limitan o prohíben alimentos que le gustan al comensal?, ¿cuál es la imagen que tiene de él mismo?, y ¿cuáles son las cogniciones y emociones que obstaculizan su autocontrol en la ingesta de alimentos?

El presente estudio tuvo como objetivo general identificar las emociones y cogniciones que presenta una persona que ingiere alimento de manera excesiva e indagar la relación entre el individuo y la comida. Los objetivos específicos fueron: definir las emociones y cogniciones asociadas a la ingesta de alimentos, identificar las emociones presentes en Alejandro cuando le limitan o prohíben alimentos que le gustan, obtener la descripción de la imagen que tiene de él mismo, e identificar las cogniciones y emociones que obstaculizan el autocontrol de la ingesta de alimentos.

\section{MÉTodo}

\section{Participante}

Se contó con la participación voluntaria de un hombre de 40 años, a quien citaremos con el nombre ficticio de Alejandro para respetar su anonimato y confidencialidad, casado, sin hijos y con una condición socioeconómica media. Si bien el aspecto físico no fue un elemento determinante para la elección del candidato, la conducta de hiperfagia que presenta Alejandro le ha ocasionado un aumento de peso considerable, ya que para sus 1.75 metros de estatura pesa 130 kilogramos. Alejandro es profesionista con posgrado en comunicaciones que fue un elemento importante para permitir la fluidez del trabajo, porque tiene las herramientas lingüísticas que le permitieron expresar sus emociones de manera clara y precisa, aunado a que la sesión de entrevista no le causó mayor impacto porque dedica su vida profesional a ello. Su sobreingesta le ha causado estragos a su salud, y pese a ser capaz de controlar gustos como el alcohol y el cigarro (que hoy ya no consume), no ha podido modificar sus hábitos alimenticios.

\section{Materiales}

1. Guía de entrevista impresa, la cual estuvo planteada de acuerdo con los siguientes ejes temáticos.

- Datos generales.

- Emociones y cogniciones asociadas a la ingesta excesiva de alimentos.

- Emociones ante la prohibición de alimentos.

- Autoconcepto.

- Cogniciones y emociones relacionadas al autocontrol de la ingesta.

2. Aplicación de grabación de audio de un celular android.

3. Consentimiento informado.

\section{Método de recolección de información}

Se optó por la entrevista minuciosa porque se quería entender las emociones, cogniciones y vivencias de una persona que presenta hiperfagia. La ventaja de esta herramienta es que permite conocer a detalle lo concerniente a nuestro tema de investigación, además de las motivaciones, creencias o sentimientos respecto a la alimentación excesiva; asimismo brindó información del significado emotivo que tiene la comida para Alejandro, los nexos o constructos mentales que se han generado respecto a la alimentación y a él mismo como reflejo de aquella.

La entrevista estuvo estructurada de acuerdo con los objetivos de investigación; primero se recabaron los datos generales; después se hicieron preguntas en torno a las emociones, cogniciones y vivencias asociadas a la ingesta excesiva de alimentos; en seguida se plantearon interrogaciones acerca de las emociones surgidas a raíz de la prohibición de alimentos; luego las preguntas giraron en torno al concepto que Alejandro tiene de sí mismo, y por último se indagó acerca de las emociones, cogniciones y vivencias relacionadas con el autocontrol de la ingesta. 


\section{Procedimiento}

Le fue planteado el objetivo de la investigación y la consideró relevante, interesante, e incluso aceptó de buena gana que alguien deseara escuchar su sentir en vez de recibir críticas y consejos hirientes. Así que mostró total disposición al participar, compartir su experiencia y su tiempo para ser entrevistado.

La entrevista tuvo una duración de 90 minutos y se efectuó en la casa de Alejandro por serle un ambiente cómodo. El lugar estaba bien ventilado, con asientos dispuestos cómodamente, sin interrupciones ni ruidos, por lo que la grabación resultó de alta calidad. Después de la presentación de la entrevistadora se le contextualizó al participante acerca del propósito del estudio y la entrevista, y se le aclaró que la entrevista sería grabada; es necesario decir que, para respetar el anonimato y confidencialidad del entrevistado, se utilizó en primera instancia un consentimiento informado, después se le comentó que su nombre sería cambiado para proteger su integridad, y qué no habría juicios de valor.

La entrevista fue transcrita en su totalidad en un procesador de texto; luego se hizo la categorización de la información, utilizando como guía los objetivos de la investigación e identificando los temas de mayor relevancia. La información recabada se analizó en el marco interpretativo de la fenomenología.

\section{Resultados}

Posterior a la aplicación, trascripción de la entrevista y estudio exhaustivo de la misma se reconocieron ocho categorías, cada una conformada por sus respectivas subcategorías.

A continuación se presenta la definición de cada una de la categorías, y después se presenta una tabla que indica la agrupación de las subcategorías.

1. Alimentos que le agradan y desagradan: listado de los alimentos que disfruta y los que no tolera.

2. Emociones al ingerir una cantidad excesiva de alimentos: el sentir de Alejandro y las consecuencias que surgen de manera mediata o inmediata a la sobreingesta de alimentos.

3. Emociones que le invaden cuando le limitan o prohíben alimentos que le gustan: sentimientos y sensaciones que tiene Alejandro cuando no puede comer lo que él quiere o la cantidad que desea porque se le limita.

4. Descripción de la imagen que tiene de él mismo: la manera en que él mismo se percibe, tanto de manera global como en lo concerniente a su sobreingesta, y de manera presente, pasada e hipotética.
5. Cogniciones o emociones que obstaculizan el autocontrol en la ingesta de alimentos: pensamientos y sentimientos causales de los que se vale Alejandro para mantener la conducta de hiperfagia.

6. Dinámica matrimonial: la dinámica que hasta ahora ha mantenido con su esposa como promotora de su conducta de comer en exceso

7. Reconocimiento de las conductas que le causan problema: las manifestaciones de Alejandro respecto a la conciencia que tiene de las causas de su alimentación en exceso.

8. Acciones tendientes al autocuidado: las acciones efectuadas o planificadas que buscan cuidar su salud y controlar su alimentación.

Tabla 1.

Categorías y subcategorías de análisis

\begin{tabular}{|c|c|}
\hline Categoría & SUBCATEGORÍAS \\
\hline \multicolumn{2}{|l|}{$\begin{array}{l}\text { 1. Alimentos que le agradan y } \\
\text { desagradan. }\end{array}$} \\
\hline \multirow{3}{*}{$\begin{array}{l}\text { 2. Emociones al ingerir una } \\
\text { cantidad excesiva de comida. }\end{array}$} & Emociones agradables. \\
\hline & Emociones negativas. \\
\hline & $\begin{array}{l}\text { Incidentes negativos por } \\
\text { comer en exceso. }\end{array}$ \\
\hline \multicolumn{2}{|l|}{$\begin{array}{l}\text { 3. Emociones que le invaden } \\
\text { cuando le limitan o prohíben } \\
\text { alimentos que le gustan. }\end{array}$} \\
\hline \multirow{3}{*}{$\begin{array}{l}\text { 4. Descripción de la imagen } \\
\text { que tiene de él mismo. }\end{array}$} & Aspectos positivos. \\
\hline & Aspectos negativos. \\
\hline & $\begin{array}{l}\text { Imagen propia si tuviese } \\
\text { control de la sobreingesta. }\end{array}$ \\
\hline \multirow{5}{*}{$\begin{array}{l}\text { 5. Cogniciones o emociones } \\
\text { que obstaculizan el } \\
\text { autocontrol en la ingesta de } \\
\text { alimentos. }\end{array}$} & Reforzamiento positivo. \\
\hline & $\begin{array}{l}\text { Emociones causantes de la } \\
\text { sobreingesta. }\end{array}$ \\
\hline & $\begin{array}{l}\text { Cogniciones autopermisivas o } \\
\text { justificantes. }\end{array}$ \\
\hline & $\begin{array}{l}\text { Evadir o ceder la } \\
\text { responsabilidad. }\end{array}$ \\
\hline & $\begin{array}{l}\text { Cogniciones que promueven } \\
\text { el autocuidado. }\end{array}$ \\
\hline 6. Dinámica matrimonial. & $\begin{array}{l}\text { Importancia de compartir } \\
\text { alimentos. }\end{array}$ \\
\hline \multicolumn{2}{|l|}{$\begin{array}{l}\text { 7. Reconocimiento de las } \\
\text { conductas que le causan } \\
\text { problema. }\end{array}$} \\
\hline $\begin{array}{l}\text { 8. Acciones tendientes al } \\
\text { autocuidado. }\end{array}$ & Metas inconclusas. \\
\hline
\end{tabular}


Los resultados obtenidos serán presentados en el mismo orden que las categorías mencionadas. Después de abrir cada categoría desarrollaremos las subcategorías correspondientes siguiendo el mismo orden. Por tanto, sírvase usar la lista que antecede como guía de la presente exposición de resultados.

Como primer acercamiento con Alejandro se le preguntó acerca de sus alimentos favoritos, otorgándonos una lista de alimentos hipercalóricos de sabores saturados y provenientes de todos los tipos alimenticios, excepto frutas y verduras. Alejandro menciona tener especial apego al pan, nutella, postres, carnes, mariscos, pollo y los sabores picantes. Sin embargo, dejó muy claro su disgusto por las comidas más saludables, como las verduras; incluso refirió: "el pepino no me gusta combinado ni en guisado, ni nada; odio los chayotes y las verduras... las calabacitas tampoco".

En cuanto a la segunda categoría, correspondiente a conocer las emociones que genera ingerir una cantidad excesiva de alimentos, notamos que por su ocurrencia son más las emociones negativas generadas que las emociones agradables. Las pocas manifestaciones que hizo relacionadas a la subcategoría Emociones agradables que se generan al comer de manera excesiva fueron: "Un momento de autoplacer. Ya al terminar la comida, llevarme el primer bocado de carne y disfrutarlo fue increíble".

Dichas emociones se limitan al momento mismo de comer. Por otra parte, las reacciones negativas parecen tener un efecto más duradero en Alejandro y las pudimos categorizar en emociones y en incidentes negativos concomitantes a la misma. Respecto a la subcategoría de emociones negativas, Alejandro mencionó la ansiedad por comer, remordimiento por haber comido demasiado, frustración, preocupación excesiva por su salud y miedo a la muerte, Sin embargo, la emoción reiterante que pudimos identificar fue la tristeza por su sobretalla y la apariencia física que presenta actualmente:

Sí; igual el sobrepeso yo creo que..., es que bueno, sinceramente yo nunca había tenido la panza del tamaño que la tengo ahorita. Hace cuatro o seis años no tenía este nivel de obesidad; entonces ya hay ocasiones en que me siento y ya siento la panza en las piernas, o ciertas posiciones que de repente me saco de onda que digo "yo no era así".

Cuando voy a medirme ropa sufro psicológicamente en mi ego; todo yo me desmenuzo, así me fracturo, me, más bien eso me desparticularizó, no sé. Mariana ha visto como me pongo triste y deprimido de saber que me tengo que comprar unos pantalones [extiende las manos a los lados mostrando el tamaño], che tamaño".
Soy tres equis [con tono de molestia y golpea la mesa con la mano]; nunca en mi vida había sido tres equis; entonces esa también es una cuestión emocional que no sabes, me pega.

Si bien esta categoría estaba enfocada inicialmente en conocer sólo las emociones del individuo, la misma fenomenología nos permite - y obliga - a atender la experiencia y vivencia de la persona, por lo que decidimos incluir la subcategoría que denominamos "incidentes negativos", que si bien causan emociones en Alejandro, usando este rubro nos permiten delimitar los sucesos que no tienen un origen intrínseco, sino en sus relaciones sociales o respuestas fisiológicas involuntarias de su propio organismo. Como hicimos referencia en líneas anteriores, existen aspectos sociales publicitarios incitadores a la hiperfagia y a la preferencia de alimentos hipercalóricos; sin embargo, desde la perspectiva de Alejandro, notamos al aspecto social no como cómplice sino como su juez y verdugo: "Incluso he masticado con la boca abierta y no me doy cuenta...".

Refiriéndose a los momentos en que tiene mucha hambre o está comiendo algo que le gusta mucho, y que su necesidad de satisfacción provoca dejar a un lado los buenos modales, provocado sentimiento de vergüenza al percatarse de su conducta. Socialmente manifiesta haber sufrido bullying y ser categorizados como gordo causando su enojo: "Las primeras veces que los escuché y que ellos no se habían dado cuenta, sí me afectó; dije 'ah, cámara, por ahí va el asunto [...] ya les digo sus cosas o me los madreo yo cuando quiero [...]. Pero sí; tuve bullying; lo viví mucho tiempo en la escuela".

Como incidente negativo a consecuencia de su hiperfagia, Alejandro mencionó de manera reiterada los malestares que ha sufrido su cuerpo, y su consecuente preocupación a su estado de salud; y como mayor motivante a controlar su ingesta, el miedo a morir, porque comentó haber sufrido un paro cardíaco y la pérdida de la vesícula, estar al límite de padecer diabetes, y en los inicios de problemas en los riñones. Asimismo manifiesta un constante agotamiento, sofocamiento, pesadez y somnolencia que le han Ilegado a afectar incluso de manera laboral: "Yo me sentí mal esta semana [...] este [...] haciendo el oficio informativo el viernes en una cobertura de prensa, aparte de que estaba haciendo calor y todo, pero yo me sentía sofocado, o sea ya no podía responder como antes".

Del análisis de la tercera categoría de las emociones que le invaden cuando le limitan o le prohíben alimentos que le gustan, nos percatarnos que la emoción primordial es la de enojo: "Es como coraje... me da coraje... pero es coraje de que me molesta que me limites 
ya sea la comida o cualquier cosa que me gusta, ‘déjame comerlo!'... porque sí me molesta que me restrinjan las cosas.... Me da coraje; llego a mentar madres, a veces mentalmente."

Este enojo se manifiesta no sólo como consecuencia de las actitudes que toman otras personas hacia él, sino incluso ante situaciones azarosas fuera de la voluntad humana. Por ejemplo, él menciona un episodio donde una familiar tira un recipiente con nachos, del cual, debido al accidente, no pudo comer ninguno, o cuando algún mesero le comunica que ya no está disponible el alimento que él deseaba: "Ya la estaba esperando y me sale con esta babosada', le digo al mesero y, este, ya después, pues me trató de controlar, y ya, este, hasta que mentalmente me hago a la idea de que se acabó; ya ni modo, y hay que seguirle".

Estas anécdotas, más que las descripciones de sus respuestas ante una limitación directa de su manera de comer, nos ilustran acerca de qué tanta es la necesidad y el apego a los alimentos por parte de Alejandro, que incluso le impiden reaccionar a la medida del suceso, causando una sobrerreacción ante situaciones que no lo ameritan. De toda la entrevista, sólo en una ocasión, al referirse tema de la imposición de límites a su manera de comer, mencionó sentirse triste por tener esa "condición" que le obliga a limitarse al comer: "De alguna manera me deja triste, enojado de que, porque tengo esta condición, tengo que limitarme para comer".

Referente a la cuarta categoría de imagen de él mismo, Alejandro mencionó lo siguiente, que corresponde a la subcategoría de aspectos positivos:

Soy muy meticuloso, muy mentalista en ese sentido; me gusta echar a trabajar la tatema en el sentido de analizar, fracturo mi todo y lo divido para analizar todas las perspectivas... soy muy persistente... Me gusta ayudar a los demás con lo que yo hago... soy muy responsable... creativo... soy muy responsable también con mis compromisos; pues sí, hasta me aplico a tal grado que a veces hasta descuido los personales y los familiares.

De la lista se puede inferir, que todos los atributos que él mismo se reconoce se limitan a su capacidad mental y laboral. Por su parte, lo correspondiente a la subcategoría de aspectos negativos, éstos fueron expresados a lo largo de la entrevista, refiriéndose tanto a su aspecto físico, emotivo, social y laboral: "Soy un glotón... soy el macho alfa: feo, fornido y formal... siento mucho la imagen, este, que me he deformado, me he descuidado de una manera muy, muy seria, y también... Soy conchudo; más bien lo veo por ese lado; no quiero sacrificarme más. Soy comodino, conchudo de lo peor...".

Asimismo, considera que las personas con que se relaciona tienen esa imagen de él; de nuevo el aspecto social tiene un gran peso negativo en el contexto propio de Alejandro:

Soy muy tímido y cohibido; a pesar de que soy líder de opinión, soy muy tímido y cohibido para poder trabajar en público; entonces mi aspecto físico tiene mucho que ver con eso; entonces cuando me comparten el video de cómo estuve trabajando en todo el escenario y demás, híjole, me daba pena verme... Por lo obeso que estoy. Vieron un gordo. Es mi autopercepción de mí mismo.

Al pedirle que describa la imagen propia si tuviese control de su ingesta de alimento, Alejandro dijo:

Estaría trabajando en aspectos mediáticos, aunque sea de cliché, pero que dejara mucho dinero... convertirme en una marca de consumo y pudieran leerme o escucharme... a lo que me refiero, es que si tuviera esa estética que tú dices, explotarla todavía más, o sea, ir con más ambición.... yo creo que me expondría en medios.... Vendría mi seguridad.

La quinta categoría, de las cogniciones o emociones que obstaculizan el autocontrol en la ingesta de alimentos, está diseñada para determinar cuál es la función fundamental de la comida en su vida, y cómo ésta tiene relación directa con las emociones, por lo que de una u otra forma busca un justificante para su conducta.

Comenzando con la subcategoría de reforzamiento positivo que Alejandro obtiene de los alimentos como parte fundamental de su vida, no porque sea algo necesario para el organismo si no porque es una forma de autopremiarse por las situaciones estresantes que, debido a su trabajo suele pasar, mismas situaciones que le causan ansiedad y nerviosismo: "De satisfacción, de premio también, de 'ya por fin, ya terminé aquî. Un momento de auto placer".

Estas emociones actúan como reforzantes de la sobreingesta en Alejandro. Por otra parte, otra vez se presenta el contexto social al ser un reforzante poderoso en la conducta: "Igual la sobremesa es importante. Yo me encargo de hacer el discurso final; nos sirven de comer; cuando estaba ahí, fue una sensación maravillosa".

En cuanto a la subcategoría Emociones causantes de la sobreingesta, Alejandro busca razones para continuar comiendo aun después de la satisfacción y a pesar 
de los conflictos personales, familiares y de salud que la hiperfagia le causa: "Sí, me da algo de ansiedad. Y a veces no tengo compromisos fuertes, pero me da la ansiedad; o yo creo que es el pretexto para buscar la comida una o dos veces sienta ansiedad por comer al día, al momento del café, pues ya viene el ataque al pan".

Por su condición cardíaca Alejandro tuvo que renunciar al cigarro, pero esto sólo se convirtió en una razón más para comer en exceso: "Quería decir que no, pero sí; pero yo también le achaco al hecho de que la ansiedad de no fumar y estas cuestiones, e incluso ya no he bebido. Yo creo que se mezcló todo, ¿no?; las melancolías de mi padre, la nicotina, el matrimonio [emoción; aguantando una leve risa], todo, así como un caldo de cultivo".

Asimismo, pese a saber lo dañino de la comida hipercalórica, cuando se le solicitó imaginar una situación ficticia donde su refrigerador estuviera lleno sólo de comida saludable, tan sólo de imaginarlo, Alejandro se sintió incómodo y con desagrado a la idea: "Ya hasta me empecé a sentir raro. Que tu boca se te haga chicharrón".

Por otra parte, en cuanto a la subcategoría que denominamos Cogniciones autopermisivas y justificantes, que a diferencia de la subcategoría anterior no busca razones para comer de más, sino que intenta disminuir o dar apariencia de inofensiva a la conducta que ha puesto su vida en peligro. Incluso hacer ejercicio no con el objetivo de cuidar su salud, sino de hacer más llevadero el remordimiento que siente al comer: "Cuando estaba haciendo ejercicio, ya tranquilo comes de más; hasta te sabe mejor la comida, Ya valía la pena; ya era una satisfacción que valía la pena".

Busca en la sociedad permiso para su conducta: "Dicen que macho sin panza es como una amiga más. Alguna vez, este, en una película de los Doors, Jim Morrison dijo '¿Qué tiene de malo ser grande como un tanque, obeso como un guerrero?', y maldita frase se me quedó muy grabada...".

O se justifica con las situaciones que le rodean:

Aparte de eso, no somos nada hábiles para cocinar en casa; entonces terminamos comiendo fuera; las dietas requieren de mucha voluntad y dinero. A lo mejor no comería a mis horas porque, este, pondría cualquier pretexto, hasta la flojera; si me levanto tarde, pues ya no desayuné; entonces ya ahí se desacomodaron las comidas ese día. Entonces, yo creo que por esa parte sí tendría conflicto familiar; entonces, parte de no seguir la dieta es decir no la quiero frustrar [a su esposa]. Me frustra el hecho que mi metabolismo ya no es el mismo, ya no quemo como antes.
Respecto a otras cogniciones o emociones que obstaculizan el autocontrol de la ingesta, pudimos apreciar la presencia de aquellas donde Alejandro evade, o responsabiliza a otros o a otras causas por su condición, como si la voluntad de comer moderadamente no le perteneciera a él: "Y, este, se nos ocurre hacerle caso a mi tío cuando dijo 'ya está el zacahuil', y nos fuimos a comer".

Asimismo, en lo referente a la subcategoría Evadir o ceder la responsabilidad, Alejandro comentó:

Le he echado la culpa a que, pues como traje tratamiento dental de brackets, pues a lo mejor también, este, me ha afectado el hecho de la mordida; a lo mejor, pero no me había dado cuenta hasta que un día me escuché yo solito y dije 'ja caray! yo no mordisqueaba así. Buscarle ahora que es light y que luego que ya no comas nada light porque te da cáncer. Es más, ni tampoco puedes comer todas juntas porque son muchas azúcares, y tampoco puedes comer acá porque te da azúcar del plátano, y todo eso no es. Me acuerdo todavía una dieta que nos dieron como de ocho días, ocho menús diferentes para la semana, y yo así [pone las palmas abiertas juntas, en forma de libro, y finge leer] ya no la quiero hacer.

Sin embargo, también encontramos, como contrapunto a esta subcategoría (Cogniciones que promueven el autocuidado), donde Alejandro manifiesta estar consciente que requiere mejorar, diferentes aspectos de su alimentación y planifica cómo retomar el ejercicio en una rutina diaria, además de que le gusta su trabajo que es enfocado hacia el deporte, y esto es un punto a su favor:

Todo va a navegar en torno a un solo eje: la lonja y lo médico, las calorías que tienes que quemar; pero esa parte de matar calorías, dices "chin, voy a tener que hacer 30 sentadillas más". Mi motivo: no morirme, que todavía ahorita no lo tengo como motivo; pero yo creo que no morirme y conservarme con saludo para mi familia. Incluso ahorita que voy a ser padrino de Camila, me está motivando también para controlarme.

Respecto a la sexta categoría (Dinámica matrimonial), Alejandro mencionó que ésta es muy importante para él, y que su esposa Mariana es una pieza fundamental en su sobreingesta. Por ejemplo, Alejando dice que a Mariana le gusta comer fuera de casa y él no puede negarse, pero también que es ella quien lo limita y que las actividades que efectúan en pro de su salud son siempre juntos. Durante toda la entrevista constantemente hizo mención a su esposa, por lo que notamos que es un pilar 
fundamental en su vida; su matrimonio es un lazo muy importante que también, de manera indirecta, ha tenido influencia en su conducta alimentaria. En el caso de la actividad física, se evidencia que es como trabajar en equipo; ambos quieren ir al gimnasio; sin embargo, en diversas ocasiones ambos han desistido. Incluso define su matrimonio como "obesidad matrimonial".

Está consciente que a ambos les hace falta cuidar su salud, y de momento es su esposa quien trata de limitarlo, lo cual a él le molesta:

Hasta Mariana se enoja: "Ashh, ya cálmate", y yo, pues es que tengo hambre todavía, y ya nada más las miradas que matan son controladoras... Se lo comento a Mariana a cada rato, pero como cada semana no logro cumplir ninguno de mis objetivos cuando viene, de que ya no voy a tomar refresco [señala una botella vacía de Coca-cola], y que no sé qué... El conflicto con mi mamá y mi esposa son el centro de control regional... hasta mi esposa me ha dicho: "oye, este, tú no masticas"; hasta he estado pensando en decirle a Mariana; "voy a tratar esta semana de comer, desayunar y cenar nada más atún [...]. Sí; porqué a lo mejor ella prefiere seguir comiendo afuera cualquier cosa. Incluso nosotros nos hemos inyectado, no botox, pero sí nos hemos inyectado cosas así, de que, este, como helecarlquina, ¿no?, quemadores, este, de grasa, y de repente sí funciona; y pum, se viene el rebote químico, entonces, este... Y, este, para estas cuestiones, pero bajamos; sí bajamos como tres kilos en un mes [...]. Sí, estamos esperando a que le baje la chamba de manera considerable porque queremos que nos trate a los dos, también para liberar la obesidad matrimonial y poder seguir [...]. Ojalá nos ayudáramos a que fuéramos menos flojos; por ejemplo, el sábado no nos levantamos tan temprano, pero pues una media hora ir a caminar, a hacer ejercicio; y el domingo igual; pero no, no logramos concretar eso; preferimos la cama [...]. Pero ya en el matrimonio sí nos vimos afectados porque, te repito, la comida fue una dinámica diferente a como estábamos en la casa materna; los dos somos culpables de esta situación, y en algún momento tendremos que abrir los ojos y tener la consciencia para apoyarnos. $Y$ siempre me ha apoyado, pero ha sido un constante cada año ver que, pues no bajamos. Como la relación es muy fuerte, pues yo creo que se sentiría ella motivada para empezar a hacer su parte.

En lo concerniente a la séptima categoría, Alejandro hace un reconocimiento de las conductas que le causan problema. Este apartado permite identificar que Alejandro está consciente de las razones por las cuales no logra mantener un control en su consumo de alimento; sin embargo, ha mantenido su conducta hasta niveles de alto riesgo para su salud.

Nunca me han prohibido nada. Estoy consciente que si como una tortilla de más, pues obviamente en algún momento tendré que hacer ejercicio [...]. Sí, este, creo que ya voy por los riñones. Yo nunca he tenido restricciones; no tengo la actitud, te digo, todavía completa, de agarrar una actitud guerrera y comenzar a trabajar, trabajar y trabajar, y a lo mejor bajar cuatro tallas. Este, tal vez la incapacidad de mantenerte a raya. Me desespera y otra vez tengo que romper; de tener mucha fuerza de voluntad para romper mi círculo vicioso, agarrar el ritmo del ejercicio, agarrar el ritmo hasta que queme y sude muchas calorías, ya no coma tanto... Tengo que salir de mi nube de confort, tengo que tener una actitud más combativa en contra de mis propios vicios. Empecé a engordar desde antes de casarme y antes de conocer a Mariana; ya después de ahí fue cuando se dio el proceso; ha sido como un proceso de 11 años de engordamiento más o menos [...]. Es que yo soy un hombre que necesita tener actitud para poder hacer las cosas; el hecho de que a veces me quedo a medias y ya no concluyo; soy demasiado indisciplinado; me falta voluntad; esto también es consecuencia de todas esas indisciplinas que he tenido. Es que son pretextos. Vuelvo a lo mismo; me pega, pero no me despierta la voluntad suficiente como para ponerme en chinga a hacer ejercicio; mi conciencia no despierta; todavía no darme cuenta del límite en el que estoy... ya empezaba a buscar pretextos, porque me preocupa más la panza; entonces comienzo a distraerme; oye, a lo mejor sí, porque he tenido bloqueos creativos que por la obesidad no he logrado concretar.

Por último, la octava categoría (Acciones tendientes al autocuidado) engloba esas acciones que está contemplando hacer para mejorar su calidad de vida. De momento hace una planeación de cómo organizar sus tiempos y poder asistir con frecuencia al gimnasio, o en su propia casa hacer sus rutinas; él considera modificar su modo de pensar para ser más constante, y de esa manera lograr su objetivo:

Sí; ahorita quiero empezar a hacer ejercicio para agarrar mi ritmo y no dejarlo; estoy contemplando ir martes y miércoles a entrenar a luchas; y los demás días, 
que de hecho aquí ya estoy comprando mis discos, ligas de tensión, una colchoneta ya para trabajar aquí y y aprovechar el tiempo.

[...]

He visto de todo; nutriólogos, bariatras, brujos, chamanes, curanderos, de todo; pero sí, ya esta semana tengo que cambiar mi mentalidad para bajar lo más que pueda; incluso también en esta lista de buenas voluntades de comer con atún, este, contemplo hacer 100 sentadillas diarias. He estado checando algunos ejercicios de cardio.

Sin embargo, muchas de estas acciones no se materializan, por lo cual identificamos la subcategoría Metas inconclusas. De manera constante intenta ser seguir rutinas de ejercicio, hacer dietas o plantearse objetivos a corto plazo, mismos que lamentablemente han sido en vano porque no logra bajar de peso, situación que lo ha frustrado:

Pienso que voy hacer mi rutina de ejercicio completa de 40 minutos, pero a los cinco minutos y ya no hago nada por las decepciones que he tenido personalmente de que siempre voy bajando algo de talla, un par de kilos, y pum [lanza el puño derecho hacia la derecha, de lado], ya sea que tengo rebote por mi propia culpa, o porque no fue efectiva la dieta. Entonces yo pensaba hacer cosas así, pero ya no lo concebí.

\section{Discusión}

Respecto a la revisión de la literatura, y de acuerdo con los resultados de nuestra investigación, podemos mencionar que para Alejandro la comida se fundamenta en el gusto por determinados alimentos, mayormente poco saludables e hipercalóricos. Como mencionamos en la parte teórica de esta investigación, comer en exceso no siempre va aparejado del sobrepeso; sin embargo, Alejandro denota una obesidad mórbida que ha puesto en peligro su vida, porque manifestó haber sufrido un paro cardiaco como consecuencia de su manera de comer, así como problemas con la vesícula que desembocaron en su extirpación, presentar infertilidad y hoy encontrarse en riesgo de padecer diabetes y complicación en los riñones, consecuencias fisiológicas que coinciden con lo descrito por Cuadro y Baile (2015).

Como dijo Sirota (2012), notamos que la conducta de comer en Alejandro es una conducta compleja generada no sólo por el hambre, sino también por varios factores biológicos, psicológicos, emocionales, nutricionales, sociales y económicos. Ahondando en las emociones de Alejandro pudimos observar que el acto de comer ocasiona en él una sensación de agrado, disfrute y alegría, y es su conexión social en círculos inmediatos y mediatos. La convivencia con su esposa, una persona muy importante en la vida de Alejandro, se da mediante la comida, así como la mayoría de las reuniones sociales a las que asiste. De esta manera el alimento queda grabado en Alejandro como una relación sujeto-alimento-afecto, tal y como mencionan Santamaría y cols. (2009). Estas emociones placenteras y recompensas sociales son un estímulo que actúa como reforzante positivo en Alejandro, incitándolo a buscar alimento cada vez que se siente ansioso, deprimido, estresado o aburrido, y generando un círculo vicioso que, por un lado, lo mantiene frustrado por su situación, mientras que por otro lado come para acallar dichas emociones. El hedonismo de Alejandro asociado al comer sobrepasa por mucho la voluntad de controlar su ingesta, porque pese a estar al borde de la muerte en una ocasión, y a estar consciente de los riesgos latentes en su vida, aún prefiere la satisfacción que le otorga la comida, y come más allá de la saciedad, y de modo excesivo, calorías y grasas al grado de ser un riesgo para la salud. Esto coincide con lo que teorizan Gracia (2009) y Santalacoma y Quiroga (2009), porque Alejandro vive en una ciudad industrializada, lo que lo lleva a tener una rutina individual que le orilla a recurrir a la comida rápida e hipocalórica tan a la mano en la ciudad donde habita.

Alejandro menciona que el exceso en su manera de comer es resultado de que, desde pequeño, nunca ha tenido limitaciones, lo cual considera le ha generado mayor dificultad para moderar su modo de alimentarse, así que hoy cualquier limitación en su manera de comer, ya sea por prescripción médica o por situaciones cotidianas, como cuando se acaba la comida, los comentarios de su esposa y su mamá causan en Alejandro disgusto, incomodidad y molestia; pese a que constantemente manifestó que está consciente de lo dañino y del alto costo emocional, laboral, familiar y de salud que le resulta comer en exceso, no encuentra la voluntad para controlar su ingesta.

Pese a que Alejandro dejó claro su gusto y necesidad por la comida, él también menciona sentir enojo y frustración cuando no puede comer lo que le gusta porque no está disponible, se ha acabado o se lo limitan; sus reacciones son negativas y exageradas ante la pérdida y no obtención del alimento que desea, mientras que la condición de su salud le ocasiona dolor y depresión; la comparación de su aspecto físico con los estándares sociales estéticos le causa emociones de enojo contra él mismo por permitirse llegar a ese estado; autorreclamos y frustración por no lograr cambios en su condición física, depresión e incluso inseguridad para lograr objetivos 
laborales. Por último, Alejandro siente remordimiento incluso al mismo momento que está sintiendo satisfacción y gusto por lo que come; por tanto, comparando las emociones generadas cuando ingiere una cantidad excesiva de alimentos y cuando le limitan o prohíben alimentos, se deduce que las emociones por su manera de comer son sobre todo negativas y que, mientras la satisfacción y disfrute por la comida es efímera, las emociones negativas son permanentes, constantes y de una gama más amplia. Sin embargo, dichas emociones negativas suelen ser acalladas con más comida. En concordancia con Kessler (2009) y Dongil y Cano (2014), los alimentos le ayudan a sentirse mejor y a bloquear emociones desagradables intensas, porque Alejandro mencionó sentir placer y tranquilidad al comer y recurrir a la comida para calmar la ansiedad. Como lo menciona Gibson (2006, citado en Peña y Reidl, 2015), pudimos ver que los estados emocionales y de ánimo influyen en su conducta alimentaria, y la alimentación modifica las emociones y estados de ánimo de Alejandro. Esta dicotomía del alimento (donde comer en exceso lo perjudica emocionalmente, pero actúa como el calmante de dichas emociones) se asemeja a lo expuesto por Miranda (2012) respecto a las conductas adictivas.

En cuanto a la imagen que tiene Alejandro de sí mismo, podemos decir, al igual que Álvarez, Franco, López, Mancilla y Vázquez (2009), Mancilla, Lameiras, Vázquez, Álvarez, Franco, Aguilar y Ocampo (2010), y Salaberria, Rodríguez y Cruz (2007), que la insatisfacción corporal de Alejandro es motivada por influencias publicitarias y socioculturales, así como una negativa autopercepción de su imagen. Sin embargo, a diferencia de los trastornos alimentarios estudiados en estas investigaciones, Alejandro no presenta la voluntad estricta, inquebrantable y metódica de una persona con anorexia, sino que se traspoló a la pérdida total de voluntad, desesperación y desesperanza de logar controlar su ingesta. Por otra parte, como imagen positiva Alejandro reconoce sus aciertos y virtudes, tiene definidos sus objetivos laborales, familiares y de cuidado personal, conoce sus defectos y los factores personales históricos que le han llevado a comer en exceso. La imagen que tiene Alejandro de él mismo en su aspecto físico es negativa, mientras que la imagen propia de características intangibles (espiritualidad, conocimientos, inteligencia, creatividad, etcétera) es positiva. Sin embargo, podemos concluir que para Alejandro la imagen propia negativa es la que tiene mayor importancia en su vida, porque esta autopercepción perjudica más el logro de objetivos que lo que sus virtudes logran fomentar su autocontrol y voluntad.
En cuanto a las cogniciones y emociones que obstaculizan el autocontrol en su ingesta de alimento, fue posible identificar las generadas por factores sociales, conductuales y personales. Alejandro dejó notar que la parte social personal, refiriéndose a la dinámica de convivencia que mantiene con su esposa, ha sido un elemento importante en la modificación de sus hábitos alimenticios, repercutiendo en su salud y fisonomía desde que estableció una relación con su esposa hace 11 años.

Es decir, durante 29 años Alejandro había mantenido una relación normal y sana con la comida, pero durante la última década ha desarrollado el hábito de comer de modo no saludable e incluso excesivo, lo que le ha traído consecuencias perjudiciales y peligrosas. Esta situación repercute no sólo en su estado físico, sino también en su estado emocional, debido a la cantidad excesiva de alimentos que ingiere.

A diferencia de lo asegurado por Aparicio (2009), Nestlé (2002; citado en López, 2004) y Gracia (2009), de que uno de los principales factores para la sobrealimentación es el ámbito social a nivel macro, como la industria alimentaria y los medios de comunicación, pudimos observar que en Alejandro los principales motivadores de la sobreingesta son las relaciones sociales cercanas que mantiene de manera personal y directa. La mayor cantidad de interacción social que realiza es por medio de la comida, por lo que la convivencia familiar se fortalece más durante este lapso, lo que impide que controle la cantidad de alimentos que ingiere.

Durante el análisis de la entrevista se observó que el reforzamiento por la comida es la principal fuerza que motiva a Alejandro a comer más allá de la saciedad; Kessler (2009) explica la relación de las reacciones neurobiológicas en la ingesta excesiva de alimentos, donde el estímulo generado por las neuronas al comer azúcar, sal y grasa sirve como reforzantes de la conducta alimentaria. La comida gratificante tiende a ser reforzante, manteniéndonos en un estado de deseo constante; en el caso de Alejandro el alimento gratificante es el azúcar, sobre todo el pan de dulce; de esta manera, los reforzantes positivos generan en él un deseo de comer más para generar el estímulo necesario para tener las emociones gratificantes que le ocasiona la comida.

Como otro factor que obstaculiza el autocontrol, es su poca voluntad constantemente refirió no tener la fuerza para mantener una dieta, hacer ejercicio, negarse a una comida que le agrada u obligarse a comer alimentos saludables.

Alejandro mostró su tendencia a evadir la responsabilidad sobre sus propios actos en cuestión de alimentos, porque de manera continua responsabiliza a otros 
o a las circunstancias de provocar su exceso al comer; esta manera de pensar es un obstáculo notorio para el autocontrol de Alejandro.

También fue posible observar que presenta constantes pensamientos autojustificantes para darse "permiso" para comer más allá de la saciedad, o pensamientos que minimizan las consecuencias de su hábito alimentario; de esta manera, las cogniciones generadas en Alejandro no sólo obstaculizan su autocontrol, sino que fomentan sus excesos.

Pudimos detectar que los estados emocionales y de ánimo influyen en la conducta alimentaria de Alejandro. Como teorizaron Miranda (2012) y Kessler (2009), y como ya se mencionó, las emociones "positivas" para Alejandro son generadas por alimentos dulces y grasosos, lo que lo lleva a ingerir más allá de la saciedad. Él utiliza la comida para aliviar la sobrecarga de emociones como la frustración por su estado físico y de salud, el estrés de su trabajo y el enojo contra los resultados siempre negativos de los diferentes tratamientos a los que se ha sometido; se molesta consigo mismo por haber perdido el autocontrol, y por ende la salud que tenía hace años; de esta manera fue posible identificar que presenta varias de las características de comer de manera emocional mencionadas en la revista The Blokehead (2015).

Si bien la sensación de satisfacción y felicidad que otorgan los alimentos son un aliciente para Alejandro a seguir comiendo, también se pudo deducir que el alimento no sólo es un estímulo, sino el refuerzo para la ingesta excesiva de alimentos; tal y como lo expone Ortuno (2015), Alejandro asocia la comida con su esposa, con quien se encuentra muy allegado; no sólo el momento de la cena es cuando conviven; también menciona que desde que su esposa trabaja lejos durante la semana, ha aumentado la cantidad de alimento que ingiere diariamente porque por las tardes, cuando está solo en casa (cuando antes estaba acompañado de Mariana), es cuando tiende a los atracones. Esto aporta información referente a, como lo diría Ortuno (2015), hambre de compañía, afecto de tranquilidad y seguridad.

La rutina diaria de Alejandro por cuestiones laborales y su falta de pericia al cocinar son dos factores personales que lo han Ilevado a recurrir a la comida rápida, alta en grasas y a base de harina accesible y fácilmente de adquirir. Estas situaciones lo obligan a tener constantes lapsos de privación alimentaria que causan una ingesta excesiva de alimento cuando puede acceder a este; por otro lado, se considera que las dietas que ha seguido Alejandro se comportan como un reforzante positivo para comer en exceso, porque tiende a comer de más los alimentos que le fueron prohibidos durante el tratamiento. Como mencionaron Vázquez y cols. (2015), la privación seguida de episodios de libre acceso a la comida ha generado el famoso "rebote" después de cada tratamiento, que no sólo perjudica la salud, sino que quebranta aún más la voluntad y confianza en bajar de peso.

Se concluye que las cogniciones que obstaculizan el autocontrol en Alejandro son la costumbre de responsabilizar a otros de su estado, autojustificarse, autopermitirse los excesos y la falta de proactividad para cambiar su situación (como es aprender a cocinar, dejar de comer en la calle, someterse a dietas, etcétera). Respecto a las emociones que le impiden ingerir una cantidad saludable de alimentos están las emociones gratificantes reforzantes que le motivan a querer más, y las emociones negativas de desconfianza en los tratamientos médicos y desesperanza en lograr bajar de peso; estas emociones negativas merman su voluntad y actúan como reforzantes positivos a continuar comiendo.

\section{Conclusiones}

El presente trabajo tuvo como objetivo general identificar las emociones y cogniciones que presenta una persona que ingiere alimento de manera excesiva e indagar la relación entre el individuo y la comida; esto se logró mediante una minuciosa entrevista hecha a un hombre de 40 años.

Los objetivos específicos de la presente investigación fueron definir las emociones y cogniciones asociadas a la ingesta de alimentos, identificar las emociones de Alejandro cuando le limitan o prohíben alimentos que le gustan, obtener la descripción de la imagen que tiene de él mismo, e identificar las cogniciones y emociones que obstaculizan el autocontrol en la ingesta de alimentos. Consideramos que la entrevista logró obtener la información necesaria para cumplir con todos nuestros objetivos.

Es necesario destacar que mediante la entrevista logramos definir de manera exitosa las emociones y cogniciones que manifiesta una persona que ingiere alimento de manera excesiva, y la relación entre el individuo y la comida. En respuesta a las preguntas de investigación y después de hacer un análisis crítico de los resultados, consideramos que se alcanzó cada uno de los objetivos, tanto general como específicos. Mediante esta investigación se logró obtener información de primera mano respecto a lo que piensa y siente una persona que come en exceso, y que la hiperfagia en Alejandro no es una conducta grata ni voluntaria - como se podría suponer al verlo disfrutar la comida-, sino una situación dolorosa y frustrante que afecta todos los ámbitos de su vida.

Así, este trabajo permitió conocer el trasfondo de una conducta que ha quedado rezagada ante la bulimia y la anorexia, y de la cual hay pocos estudios en compa- 
ración a los efectuados en dichos trastornos alimenticios. Comer en exceso, como lo demuestra Alejandro, tiene tintes de problemas emocionales, de voluntad, determinación, trastornos alimenticios y conductas adictivas.

Se proponen futuras investigaciones para conocer el origen del problema y determinar qué aspectos de la vida de una persona le llevan a "optar" por desahogar sus emociones mediante la comida. Como aprendimos de Alejandro su débil voluntad es uno de sus principales obstáculos para contenerse ante la comida. A diferencia de otras conductas adictivas donde sirve alejarse voluntariamente de situaciones de riesgo para no tener que poner a prueba la voluntad, la comida no es una opción; es una necesidad vitalicia a la cual Alejandro se enfrenta día a día.

Por ello consideramos interesante $-\mathrm{y}$ necesariofuturas investigaciones enfocadas a otorgar datos necesarios que permitan diseñar intervenciones que logren fortalecer la voluntad de quienes, como Alejandro, no logren mantenerse firmes ante una dieta saludable.

Una limitación del presente ensayo es que sólo se trabajó con un participante en una única entrevista de 90 minutos, por lo cual sería muy útil complementar la información recabada con más entrevistas a Alejandro y a otras personas que presenten ingesta excesiva de alimentos. Asimismo, se propone un trabajo similar al presente, pero enfocado a conocer y entender de manera minuciosa la razón por la cual personas como Alejandro han creado constructos mentales negativos alrededor de alimentos saludables.

Como se pudo observar, Alejandro no manifestó desagrado por los sabores de las verduras, simplemente un odio hacia ellas. Esto abre la puerta al cuestionamiento de si el disgusto por dicho alimento proviene del desagrado generado en su boca o en su mente; y si es generado de manera cognitiva, se debe a reforzamientos negativos en la infancia o recuerdos aversivos, o por alguna de las distorsiones cognoscitivas como las mencionadas por Garner y Benis (1982; citados por Santalacoma y Quiroga, 2009), que en este trabajo no alcanzamos a descubrir.

\section{Referencias}

Álvarez, G., Franco, K., López, X., Mancilla, J. \& Vázquez, R. (2009). Imagen corporal y trastornos de la conducta alimentaria. Revista de Salud Pública. 11(4), 568-578. Recuperado de http://www.scielosp.org/pdf/rsap/v11n4/v11n4a08.pdf

Aparicio, A. (2009). Felicidad y aspiraciones crecientes de consumo en la sociedad postmoderna. Revista Mexicana de Sociología. 71(1), 131-157. Recuperado de http://www. scielo.org.mx/pdf/rms/v71n1/v71n1a4.pdf

Cuadro, E. \& Baile, J. (2015). El trastorno por atracón: análisis y tratamientos. Revista Mexicana de Trastornos Alimentarios. 6(2), 97-107. Recuperado de http://www. redalyc.org/pdf/4257/425743626004.pdf

Dongil, E. \& Cano, A. (2014). Guía de alimentación, PHS, Promoción de hábitos saludables. España: Sociedad Española para el Estudio de la Ansiedad y el Estrés (SEAS). Recuperado de http://www.bemocion.mscbs.gob.es/ comoEncontrarmeMejor/guiasAutoayuda/docs/guia de alimentacion.pdf

Gracia, M. (2009). Qué y cuánto comer, tomando medidas frente a las sociedades obesogénicas. Salud Colectiva. 5(3), 363-376. Recuperado de http://www.redalyc.org/ pdf/731/73111844005.pdf

Kessler, D. (2009). The end of overeating: Taking control of the insatiable American appetite. [El final de comer en exceso: Tomando control del apetito americano insaciable]. Nueva York: Rodale Inc. Recuperado de: https://books. google.com.mx/books?isbn=1605294578

López, A. (2004). ¿Por qué comes lo que comes? Reflexiones sobre la alimentación moderna. ¿Cómo ves? Revista de divulgación de la ciencia de la UNA. 6(64). Recuperado de

http://www.comoves.unam.mx/numeros/articulo/64/por-quecomes-lo-que-comes-reflexiones-sobre-la-alimentacionmoderna

Mancilla, J., Lameiras, M., Vázquez, R., Álvarez, G., Franco, K., Aguilar, X. \& Ocampo, M. (2010). Influencias socioculturales y conductas alimentarias no saludables en hombres y mujeres de España y México. Revista mexicana de trastornos alimentarios. 1(1), 36-47. Recuperado de http://www.scielo.org.mx/pdf/rmta/v1n1/v1n1a5.pdf

Miranda, M. (2012). Comiendo compulsivamente: Algunas teorías para explicar por qué "no puedes comer sólo una". Revista Digital Universitaria. 13(3), 3-12. Recuperado de: http:// www.revista.unam.mx/vol.13/num3/art36/art36.pdf

Ortuno, I. (2015). Devorando emociones: Hambre real o hambre emocional. Revista de Gastronomía. 2(2), 21. Recuperado de http://www.isabelortunopsicologia.com/articulos/ Revista de Gastronomia 2015 Maria Isabel Ortuno.pdf

Pascual, A., Etxebarria, I., Cruz, M. \& Echeburúa, E. (2011). Las variables emocionales como factores de riesgo de los trastornos de la conducta alimentaria. International Journal of Clinical and Health Psychology. 11(2), 229247. Recuperado de https://www.researchgate.net/ publication/228660626 Las variables emocionales como_factores_de_riesgo_de_los_trastornos_de_la_ conducta_alimentaria1

Peña, E. \& Reidl, L. (2015). Lasemocionesyla conducta alimentaria. Acta de Investigación Psicológica - Psychological Research Records. 5(3), 2182-2194. Recuperado de http://www. redalyc.org/pdf/3589/358943649006.pdf

Pérez, D., Rivera, J. \& Ortiz, L. (2010). Publicidad de alimentos en la programación de la televisión mexicana: ¿Los niños están más expuestos?. Salud Pública de México. 52(2), 119-126. Recuperado de http://www.scielo.org.mx/pdf/ spm/v52n2/v52n2a03.pdf

Ponce, C., (2007). Psicoterapia cognitivo-conductual para la obesidad. En N. Hernández, y J. Sánchez. (coords.). Manual de Psicoterapia Cognitivo-Conductual para trastornos de la Salud (pp. 227-247). Libros en 
red. Recuperado de https://books.google.com.mx/ books?id=EzlwZg aH6AC\&printsec=copyright\&redir esc=y\#v=onepage\&q\&f=false

Salaberria, K., Rodríguez, S. \& Cruz, S. (2007). Percepción de la imagen corporal. Osasunaz. Cuadernos de Ciencias de la Salud. 8, 171-183. Recuperado de http://www. eusko-ikaskuntza.org/es/publicaciones/percepcion-de-laimagen-corporal/art-17002/

Santacoloma, A. \& Quiroga, L. (2009). Perspectivas de estudio de la conducta alimentaria. Revista Iberoamericana de Psicología: Ciencia y Tecnología. 2(2), 7-15. Recuperado de http://revistas.iberoamericana.edu.co/index.php/ ripsicologia/article/view/180/314

Santamaría, S., Escobar, J., Rodríguez, V., Tolentino, A., Barranco, J., Hurtado, G. y Jiménez, L. (2009). Aspectos psicológicos del hombre y su alimento: Transitando de la naturaleza a la biotecnología en pro de la calidad de vida. Revista Científica Electrónica de Psicología ICSa-UAEH. 8, 4054. Recuperado de https://repository.uaeh.edu.mx/ bitstream/bitstream/handle/123456789/12191/2. pdf?sequence=1\&isAllowed =y

Sirota, M. (2012). Emotional Overeating: Know the Triggers, Heal your Mind, and never diet again. [Comer en exceso emocional: Conoce los detonantes, Sana tu mente y nunca hagas dieta otra vez]. California: ABC-Clio. Recuperado de https://books.google.com.mx/books?isbn=144080401X
The Blokehead (2015). Pon fin a tu apetito emocional. Consejos y estrategias para dejar de comer por causas emocionales en 30 días. España: Babelcube Inc. Recuperado de https://books.google.com.mx/ books? id =UvOtCQAAQBAJ\&lpg=PT4\&dq=pon $\% 20$

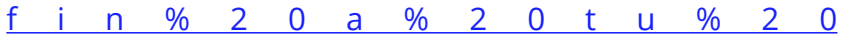
apetito\&hl=es\&pg=PP1\#v=onepage\&q=pon $\% 20$ fin $\% 20$ a\%20tu\%20apetito\&f=false

United Nations Children's Fund, (s.f.). El doble reto de la malnutrición y la obesidad. ¿Qué hacemos? Salud y nutrición. Recuperado de https://www.unicef.org/mexico/ spanish/17047 17494.html

Vázquez, L., López, A., Martínez A., Rodríguez, J., Aguilera, V. \& Esponoza, A. (2015). Privación, comilona y obesidad. En A. López, A. Martínez y P. López. (coords.). México obeso. Actualidades y perspectivas (pp. 140-154). Guadalajara: Editorial Universitaria. Recuperado de https://www. researchgate.net/publication/278028072 Mexico Obeso_Actualidades_y Perspectivas 


\section{Meta-Análisis del Artículo}




\section{Dimensión Cuantitativa}

\section{Perfil de Evaluación entre pares}
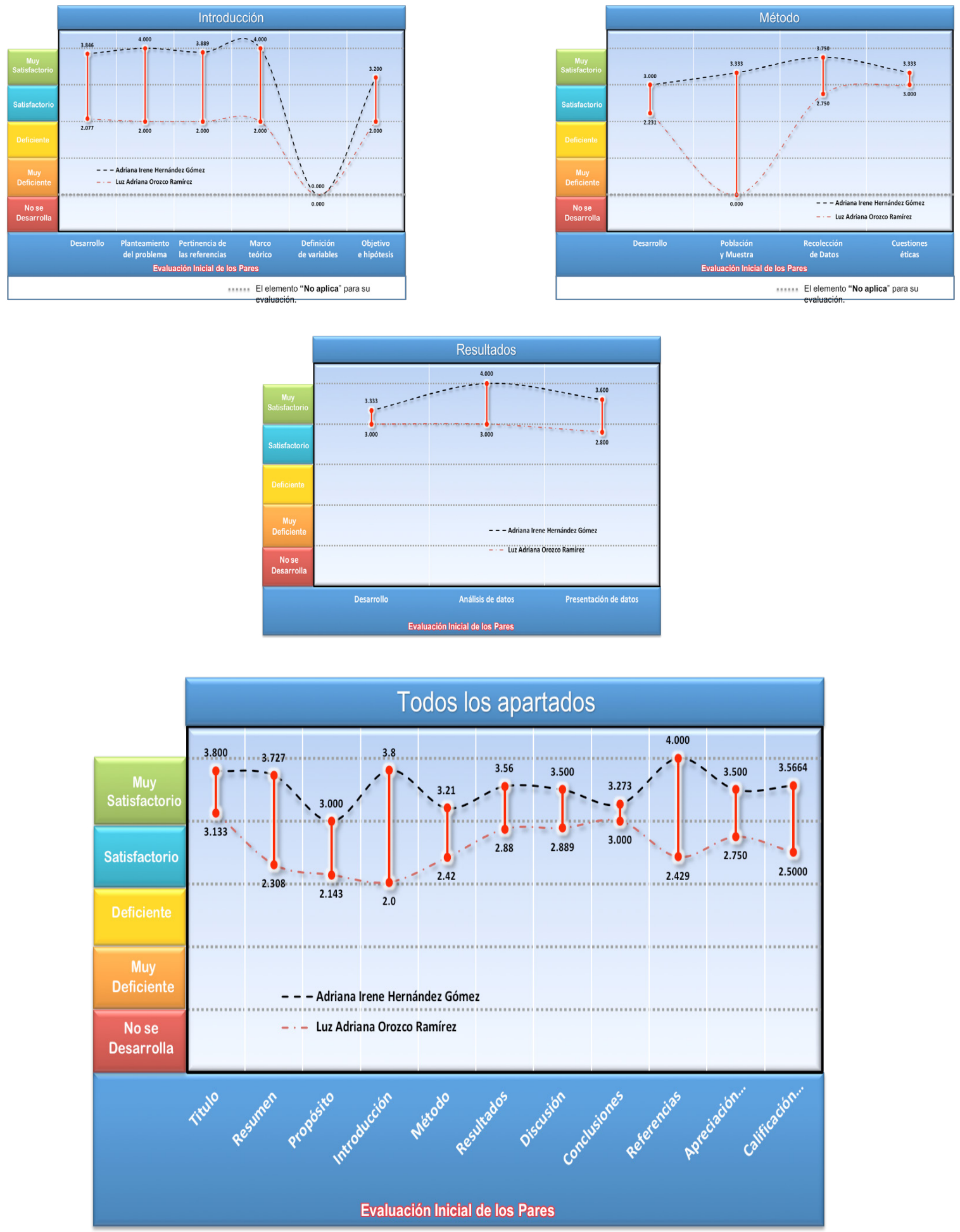


\section{Índice de Concordancia}

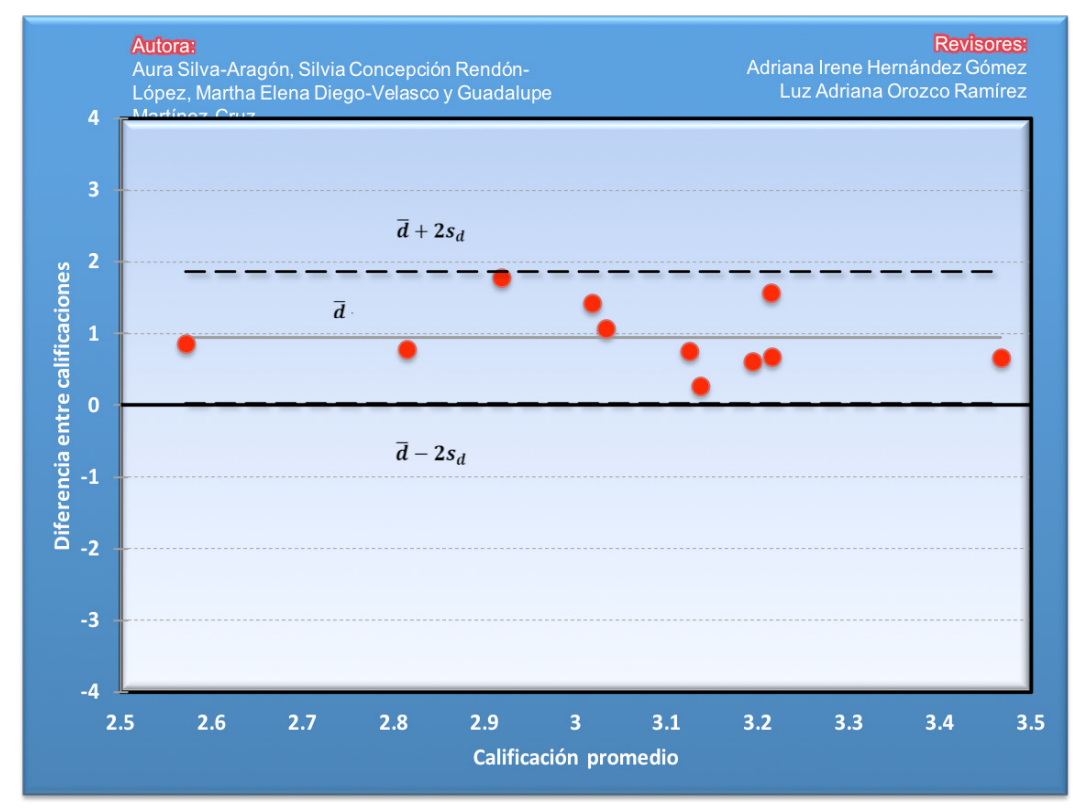

Índice de Acuerdo

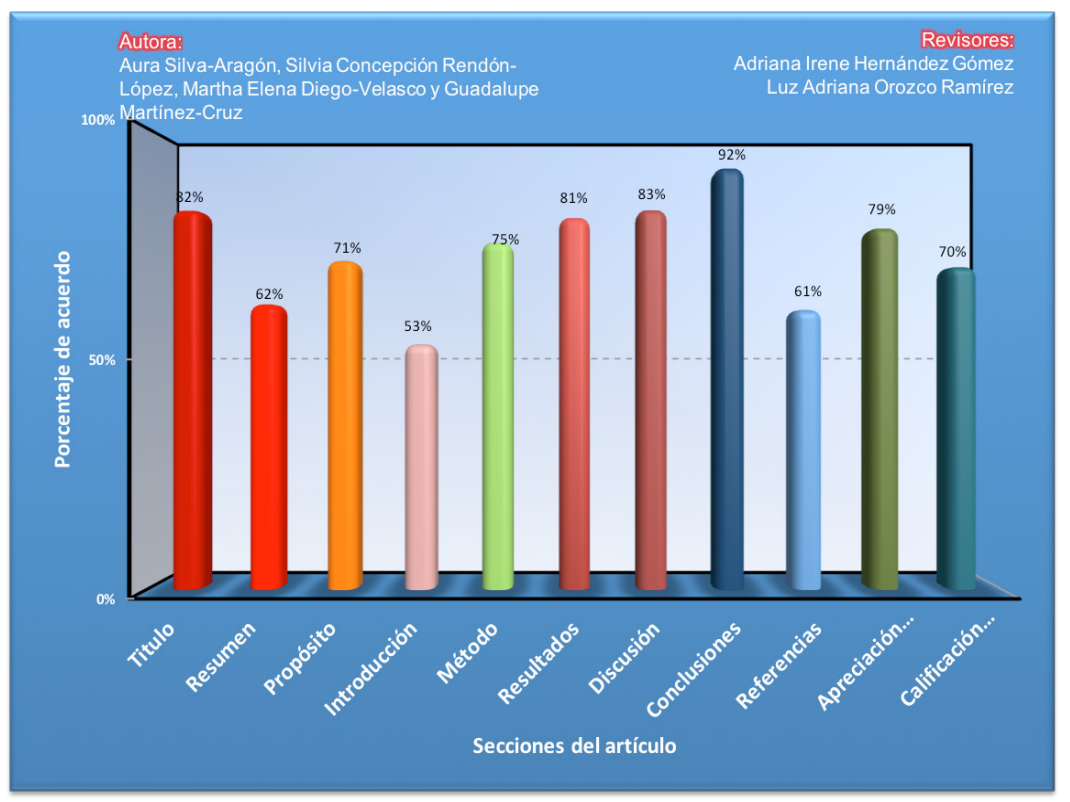




\begin{tabular}{|c|c|}
\hline Revisor 1 & Revisor 2 \\
\hline Luz Adriana Orozco Ramirez & Adriana Irene Hernández Gómez \\
\hline \multicolumn{2}{|c|}{ Título/Autoría } \\
\hline $\begin{array}{l}\text { El titulo debe de ser más especifico, aunque menciona } \\
\text { las variables analizadas, sugiero que pueda cambiarse a } \\
\text { "Emociones, vivencias y cogniciones de un hombre con } \\
\text { hiperfagia; estudio de caso " ya en método se aborda } \\
\text { que se va a analizar de manera cualitativa. Solo se en- } \\
\text { cuentra el correo del primer autor. }\end{array}$ & $\begin{array}{l}\text { En las palabras clave podría incluirse: estudio de caso o } \\
\text { investigación cualitativa. Respecto a la autoría múltiple, } \\
\text { podría explicarse un poco más la contribución de cada } \\
\text { autora, ya que se realizó una sola entrevista, y son tres las } \\
\text { autoras se les incluye en el trabajo de campo. }\end{array}$ \\
\hline \multicolumn{2}{|c|}{ Resumen } \\
\hline $\begin{array}{l}\text { No hay una conclusión concreta, solo la importancia de } \\
\text { seguir investigando sobre el tema. Se sugiere que el re- } \\
\text { sumen cumpla con los criterios de } 150 \text { palabras. Y que } \\
\text { quede muy bien especificado la aportación del estudio. }\end{array}$ & $\begin{array}{l}\text { Respecto de la descripción de resultados en el resumen, se } \\
\text { recomienda estos se apeguen mucho más al análisis feno- } \\
\text { menológico propuesto y no sólo de manera descriptiva. } \\
\text { Igualmente, se recomienda que en su descripción de las } \\
\text { conclusiones se muestre mayor profundidad, en términos } \\
\text { del vínculo que hay entre el marco teórico de referencia y } \\
\text { lo derivado del análisis de la entrevista. }\end{array}$ \\
\hline \multicolumn{2}{|c|}{ Próposito del Estudio } \\
\hline $\begin{array}{l}\text { No queda claro el propósito del estudio solo indica que } \\
\text { es cualitativo con entrevista a profundidad, pero no se- } \\
\text { ñala la importancia o relevancia del estudio. }\end{array}$ & \\
\hline \multicolumn{2}{|c|}{ Introducción } \\
\hline $\begin{array}{l}\text { Se recomienda que la introducción tenga correspon- } \\
\text { dencia con las variables estudiadas, cogniciones, emo- } \\
\text { ciones, vivencias personales, ya que se encuentran se- } \\
\text { ñalados como factores, seria conveniente señalar que } \\
\text { estos factores se encuentran relacionados con la hiper- } \\
\text { fagia. Ahora la mayoría de los estudios señalados co- } \\
\text { rresponden a adolescentes o bien universitarios y que } \\
\text { hay de la población adulta?? Pues la edad de la persona } \\
\text { del estudio de caso es de } 40 \text { años. Igual no habla de da- } \\
\text { tos con respecto al género. Si se da deforma distinta es- } \\
\text { tos factores relacionados tomando en cuenta el género. }\end{array}$ & $\begin{array}{l}\text { Se sugiere integrar al menos una definición de hiperfagia, } \\
\text { que acompañe al lector en todo el trabajo, ya que en oca- } \\
\text { siones se sustituye este término con "consumo excesivo de } \\
\text { alimentos" u otras acepciones similares que pueden pres- } \\
\text { tarse a ambigüedad. }\end{array}$ \\
\hline
\end{tabular}




\begin{tabular}{|c|c|}
\hline Revisor 1 & Revisor 2 \\
\hline \multicolumn{2}{|c|}{ Método } \\
\hline $\begin{array}{l}\text { No explica el diseño general del estudio, al igual la for- } \\
\text { ma en que se llevo a cabo el análisis cualitativo de la } \\
\text { información obtenida. }\end{array}$ & $\begin{array}{l}\text { En investigación cualitativa es especialmente importante } \\
\text { especificar las características de los participantes. En este } \\
\text { estudio, y derivado también de la revisión teórico-empí- } \\
\text { rica realizada, se vuelve fundamental especificar, además } \\
\text { de lo ya señalado, las condiciones socioeconómicas del } \\
\text { participante, así como el tiempo que presenta con la pro- } \\
\text { blemática de hiperfagia, ya que esta información permi- } \\
\text { te una mirada profunda de la problemática y un análisis } \\
\text { mucho más preciso. El método se describe de manera } \\
\text { somera, sería necesario especificar un poco más con } \\
\text { respecto al procedimiento, en términos sobre todo de la } \\
\text { manera en que se hace el análisis fenomenológico de la } \\
\text { entrevista. Así también es importante que las categorías } \\
\text { de análisis correspondan también a la revisión teórica de } \\
\text { la problemática, si no, pareciera una cuestión más incli- } \\
\text { nada a la clínica especificada en el caso estudiado, y que } \\
\text { no permitirían descubrir más sobre el fenómeno mismo. } \\
\text { Es decir, aunque dentro de los fines de la investigación } \\
\text { cualitativa no se encuentra hacer generalizaciones, sino } \\
\text { destacar las paricularidades, también puede pensarse de } \\
\text { manera general en la problemática. }\end{array}$ \\
\hline \multicolumn{2}{|c|}{ Resultados } \\
\hline $\begin{array}{l}\text { Los resultados se presentan en base a las } 8 \text { categorías } \\
\text { analizadas en el análisis de la entrevista, presenta cada } \\
\text { una de las categorías y ejemplos textuales de las mismas }\end{array}$ & $\begin{array}{l}\text { El análisis de los resultados son correctos, de acuerdo a } \\
\text { los objetivos planteados; sin embargo, permanecen a un } \\
\text { nivel meramente descriptivo. }\end{array}$ \\
\hline \multicolumn{2}{|c|}{ Discusión } \\
\hline $\begin{array}{l}\text { Las limitaciones del estudio se abordan en las conclu- } \\
\text { siones }\end{array}$ & $\begin{array}{l}\text { Resultaría muy enriquecedor hablar de las limitaciones } \\
\text { del estudio, por ejemplo del hecho de que se trate de un } \\
\text { solo participante y que se haya hecho únicamente una } \\
\text { entrevista de } 90 \text { minutos de duración. }\end{array}$ \\
\hline \multicolumn{2}{|c|}{ Conclusiones } \\
\hline $\begin{array}{l}\text { Se centra en los principales hallazgos sobre emociones, } \\
\text { vivencias y cogniciones así como se planteo en los obje- } \\
\text { tivos, ademas de señalar las investigaciones futuras }\end{array}$ & $\begin{array}{l}\text { Las conclusiones siguen centrándose principalmente en } \\
\text { el caso estudiado, y no permiten visualizar la problemá- } \\
\text { tica de la hiperfagia de manera general. }\end{array}$ \\
\hline \multicolumn{2}{|c|}{ Referencias } \\
\hline $\begin{array}{l}\text { las referencias no cumplen con más del } 50 \% \text { de los úl- } \\
\text { timos } 5 \text { años, se incluyen solo } 21 \text { referencias sería con- } \\
\text { veniente ampliar con estudios de caso sobre pacientes } \\
\text { adultos con sobre ingesta }\end{array}$ & $\begin{array}{l}\text { Referencias adecuadas, actualizadas, suficientes y co- } \\
\text { rrectas en estilo. }\end{array}$ \\
\hline
\end{tabular}


